35. Лутовинов В.И. Патриотизм и его формирование в обществе и Вооруженных Силах // Военная мысль. 2000. № 4. С. 38-42.

36. Караковский В.А. Стать человеком. Общечеловеческие ценности - основа целостного учебно-воспитательного процесса. М., 1993 [Электронный ресурс] // http:// trc-olhon.ucoz.ru/zamestitelu/karakovskiystatshelovekom.doc.

37. Лихачев Б.Т. Введение в теорию и историю воспитательных ценностей (теоретико-исторический анализ воспитательных ценностей в России в XIX и ХХ вв.). Самара: СИУ, 1997. 85 с.

38. Лихачев Д.С. Раздумья / сост. и общ. ред. Г.А. Дубровский. М.: Детская литература, 1991.318 с.

39. Лебедева О.В. Условия разрешения противоречий в процессе патриотического воспитания школьников // Воспитание школьников. 2015. № 7. C. $3-11$.

\title{
THE PROBLEM OF PATRIOTIC EDUCATION IN RUSSIAN PEDAGOGICAL THOUGHT
} (C) 2016

\author{
N.I. Vereshchagina, teacher of history and social science \\ Secondary School №2 with Profound Studying of Separate Subjects of Ust-Kinelsky Urban-Type Settlement \\ of Kinel Urban Okrug of Samara Region, Kinel, u.t.s. Ust-Kinelsky (Russia)
}

\begin{abstract}
The paper explains the importance of the problem of student patriotic education and emphasizes the need to create a culture of patriotic students. The concept of «patriotism» is a basic component in the formation of patriotic culture of students. Critical thinking scientific knowledge about patriotism, methods and techniques of education lead to an understanding that the system of activities in the field of patriotic education requires changes based on education of spiritual values and development of the concept of formation of student patriotic culture. A central element of patriotic education as the basis of patriotic culture is a philosophical theory of values. In modern state programs and documents it is indicated that patriotism is one of the enduring and ineradicable values. Education value and moral oriented personality, with a sense of patriotism, responsibility and other qualities is one of the main tasks of the state policy in the field of education at the present stage of society development. Students - future citizens must be prepared to confront the global challenges of the modern era, they should be highly moral, creative, competent citizens who are aware of the responsibility for the present and the future of their country. Analysis of scientific pedagogical literature leads to the conclusion that the scientific community addresses the problem of patriotism in the historically urgent tasks of development of society in periods of social crisis. Scientists and public figures from different eras are unanimous in saying that patriotism is firstly love for the country and secondly the activity aimed at the goodness of the motherland, to the defense of its interests, willingness to serve the motherland.

Keywords: patriotism; patriotic culture; patriotic education; value; motherland; love for the motherland; the genesis of the development of ideas about patriotism; patriot; student; education; the contradictions in the education of patriotism; the national pedagogical thought.
\end{abstract}

\section{УДК 378:001.891}

\section{НАПРАВЛЕННОСТЬ ЛИЧНОСТИ И МОТИВЫ ВЫБОРА ПРОФЕССИИ: ТОЧКИ ПЕРЕСЕЧЕНИЯ}

(C) 2016

T.А. Горшкова, кандидат педагогических наук,

доцент кафедры методик математического и информационно-технологического образования

E.М. Громова, кандидат педагогических наук, доцент кафедры методик математического и информационно-технологического образования

Д.И. Беркутова, кандидат педагогических наук, доцент кафедры технологий профессионального обучения Ульяновский государственный педагогический университет имени И.Н. Ульянова, Ульяновск (Россия)

Аннотаиия. В данной статье актуализирована проблема изучения особенностей планирования профессиональной карьеры провинциальной молодежью. Авторами проанализированы основные научные и методологические подходы в отношении задачи мирного сосуществования и взаимного обогащения различных культур, а также в аспекте построения карьеры молодежью. Рассмотрена теория мотивации Фредерика Герцберга. Согласно теории, Ф. Герцберг создал двухфакторную модель, где первая группа факторов (гигиенические) удерживает личность на работе, вторая группа (мотиваторы) - мотивирует к работе. Используя тест Ф. Герцберга, можно определить структуру мотивации и выделить превалирующие факторы удовлетворенности или неудовлетворенности трудом. Экспериментальная выборка респондентов составлялась из числа студентов 4 курса очного отделения факультета технологии и дизайна УлГПУ. Диагностирование респондентов проводилось по тесту Ф. Герцберга для отслеживания взаимосвязи направленности личности и мотивов выбора профессии. Для выявления направленности личности использовалась ориентационная анкета Б. Басса. Данная методика позволяет выявить степень выраженности трех основных ориентаций личности: направленность на себя, на взаимодействие с партнерами и на задачу. В статье приводятся результаты проведенных диагностик, доказывающих, что мотивы выбора профессии личностью и ее направленность имеют точки пересечения. Полученные материалы могут служить основой для дальнейших разработок теоретических и практических аспектов проблемы подготовки провинциальной молодежи к планированию профессиональной карьеры. 
Ключевые слова: профессия; выбор профессии; профессиональная карьера; провинциальная молодежь; полиэтничность; полиэтнический регион; профессиональная идентификация; профессиональная идентичность; студент; направленность личности; теория мотивации Ф. Герцберга; гигиенические факторы; мотиваторы.

В настоящее время образовательная политика в России находится на пути активного поиска решения вопросов подготовки современной молодежи к построению профессиональной карьеры в многонациональном регионе. Полиэтничность является объективной составляющей многомерной структуры всего российского общества, в том числе и Поволжского региона. Симбирско-Ульяновский регион находится в самом центре России. Среднее Поволжье - это географическое и историческое пространство столкновений интересов великого множества народов, которые научились мирно сосуществовать на протяжении многих веков. В национальных культурах татар, чуваш, мордвы и русских, составляющих сегодня основные диаспоры Ульяновской области, представлены опыт и мудрость тюркской, финно-угорской и славянской и иных культур. Такое переплетение народов ставит перед региональным образовательным пространством сложные задачи формирования дружественных межнациональных отношений, развития этнической толерантности $[1$, с. 6].

В то же время современное общество характеризуется повышением уровня полиэтничности за счет роста притока трудовых мигрантов из стран бывшего СССР, что в сочетании с глубоким социальноэкономическим кризисом, неустроенностью жизни большей части населения, безработицей и конкуренцией на рынке труда за вакантные рабочие места, усиливает нестабильность общества.

В данном контексте нельзя не учитывать и феномен «этнического ренессанса», который захватил сегодня большую часть мира, и в результате которого, сегодня наблюдается всплеск национализма и ксенофобии среди коренных жителей, что создает взрывоопасную обстановку и угрожает целостности страны.

При этом необходимо учитывать, что самая динамичная часть населения в силу ряда причин, таких как еще не полная сформированность ценностей и этнических установок, юношеский кризис идентичности, неустроенность в профессии - это молодежь [2].

Bce выше сказанное, на наш взгляд, указывает на потенциальную нестабильность в молодежной среде Поволжья и определяет основную цель нашего психолого-педагогического исследования - изучение особенностей планирования профессиональной карьеры провинциальной молодежью.

В связи с этим перед современной педагогической наукой выдвигается целый комплекс новых теоретических и практических проблем, связанных с решением задачи мирного сосуществования и взаимного обогащения различных культур, его составляющих: под руководством Г.Д. Дмитриева создана теория многокультурного образования; складывается традиция поликультурного образования (О.В. Аракелян, В.А. Ершов, М.Н. Кузьмин, В.В. Макаев, 3.А. Малькова, В.Б. Новичков, Л.Л. Супрунова [3] и др.); разрабатывается теория воспитания этики межнационального общения (В.Д. Ботнарь, Ю.С. Горбачева, Э.К. Суслова и др.); ведутся исследования в области мультикультурного образования (А.Г. Абсалямова, Н.Б.
Крылова, Е.Ю. Литвиненко, А.В. Шафрикова и др.); воспитанию национального самосознания и межэтнической толерантности посвящены работы Г.Г. Абдулкаримова, В.Х. Абэляна, Р.Т. Гарданова, Д.В. Зиновьева, З.Ф. Мубиновой [4], В. Троицкого, Л.С. Ядрихинской; развивается этнопедагогика (Г.Н. Волков, И.И. Валеев, Е.И. Грекова, И.А. Дадов, В.С. Кукушин [5], Д.И. Латышева, З.Г. Нигматов, М.Г. Тайчинов, Ф.Ф. Харисов и др.).

В аспекте построения карьеры молодежью, основными теоретико-методологическими принципами нашего исследования являются следующие научные подходы: концепция становления личности как субъекта своей профессиональной деятельности (Е.М. Борисова, Е.А. Климов [6], А.К. Маркова, Н.С. Пряжников [7], И.В. Самоукина, А.Р. Фонарев, В.Д. Шадриков и др.); концепция профессионализма (А.К. Маркова); концепция профессионального становления в контексте развития карьеры (Д. Сьюпер [8]); теория профессионального развития (Е. Гинцберг, Ф. Парсонс, Д. Сьюпер); концепция и идеи личностно ориентированного образования (Н.А. Алексеев, Е.В. Бондаревская, И.А. Колесникова, К. Роджерс, Е.А. Савина, Ю.В. Сенько, В.В. Сериков, В.И. Слободчиков, А.П. Тряпицына, Е.Н. Шиянов, И.С. Якиманская); теория изучения индивидуальной образовательной траектории (маршрута) (Т.М. Ковалева, Н.В. Рыбалкина, А.Б. Воронцов, С.В. Воробьева, Г.Н. Прозументова, А.В. Хуторской, А.Н. Тубельская, Е.А. Александрова, Н.Н. Суртаева) [1, с. 7-9].

Система образования как один из главных государственно-общественных институтов, ответственных за функционирование и развитие общества, обязана создать и реализовать условия, которые позволят современной провинциальной молодежи «найти свое место в мире», т.е. идентифицироваться в профессиональном и этнокультурном плане, для чего в первую очередь необходимо сформировать адекватные мотивы выбора профессии [9].

Итак, нас интересует, прежде всего, мотивационно-ценностная составляющая профессиональной идентификации [10]. Следовательно, для проведения результативной диагностики, необходимо вычленить те ведущие характеристики личности, которые и определяют ее мотивационно-ценностную ориентацию в профессии.

Проводя анализ современных исследований, мы выяснили, что основополагающей доминантой в профессиональной идентификации является направленность личности, поскольку под направленностью личности можно понимать мотивационно-потребностные установки личности, определяющиеся ярко выраженными векторными потребностями, которые сообразуются с целями и задачами, в конечном итоге направляя деятельность и поведение человека [11].

Кроме того, как отмечает Н.Ю. Спиридонова, направленность личности представляет собой свойство личности, задающее вектор ее ценностносмысловых отношений «индивид-общество», которое формируется в процессе развития личности в системе общественных отношений [12]. 
Для диагностики направленности личности в настоящее время широко используется ориентационная анкета, впервые опубликованная американским психологом Б. Бассом в 1967 г. и модифицированная чешскими учеными В. Смекалом и М. Кучером [13].

Методика позволяет выявить степень выраженности трех основных ориентаций личности: направленность на себя, на взаимодействие с партнерами и на задачу. С помощью методики выявляются следующие направленности:

1. Направленность на себя (Я) - ориентация на прямое вознаграждение и удовлетворение безотносительно работы и сотрудников, агрессивность в достижении статуса, властность, склонность к соперничеству, раздражительность, тревожность, интровертированность.

2. Направленность на общение (O) - стремление при любых условиях поддерживать отношения с людьми, ориентация на совместную деятельность, но часто в ущерб выполнению конкретных заданий или оказанию искренней помощи людям, ориентация на социальное одобрение, зависимость от группы, потребность в привязанности и эмоциональных отношениях с людьми.

3. Направленность на дело (Д) - заинтересованность в решении деловых проблем, выполнение работы как можно лучше, ориентация на деловое сотрудничество, способность отстаивать в интересах дела собственное мнение, которое полезно для достижения общей цели.

Предложенные направленности не являются изолированными, а обычно сочетаются и у каждого человека имеют свою степень выраженности.

Известно, что направленность личности достаточно динамична, и взаимосвязана с взаимовлияющими мотивами [14]. Поэтому, в качестве еще одной методики мы применили тест Ф. Герцберга для отслеживания взаимосвязи направленности личности и мотивов выбора профессии.

Теория мотивации Фредерика Герцберга [15] появилась в связи с растущей необходимостью выяснить влияние материальных и нематериальных факторов на мотивацию человека. Фредерик Герцберг создал двухфакторную модель, которая показывает удовлетворенность работой:

- факторы, удерживающие на работе (гигиенические факторы) -нормальные условия труда, достаточная заработная плата, политика фирмы и администрации, межличностные отношения с начальниками, коллегами и подчиненными, степень непосредственного контроля за работой, статус;

- факторы, мотивирующие к работе (мотиватоpbl) - успех, продвижение по службе, признание и одобрение результатов работы, высокая степень ответственности за выполняемое дело, возможности творческого и делового роста.

Гигиенические факторы связаны со средой, в которой выполняется работа, с самовыражением личности, ее внутренними потребностями. Гигиенические факторы соответствуют физиологическим потребностям, потребности в безопасности и уверенности в будущем. По теории Герцберга, отсутствие или недостаток гигиенических факторов приводит к неудовлетворённости человека своей работой. Но, если они Самарский научный вестник. 2016. № 3 (16) представлены в достаточном объёме, сами по себе они удовлетворения не вызывают и не способны мотивировать человека к нужным действиям.

Вторая группа факторов мотивации связана с характером и сущностью самой работы.

Используя тест Ф. Герцберга можно определить структуру мотивации и выделить превалирующие факторы удовлетворенности или неудовлетворенности трудом. На каждый вопрос опрашиваемому предоставляется 5 баллов, которые нужно распределить между двумя вариантами ответа $(5: 0 ; 4: 1 ; 3: 2$; $2: 3 ; 1: 4 ; 0: 5)$. По окончании опроса нужно просуммировать баллы, набранные в ответах, обозначенных буквами.

Результаты теста нагляднее изображать в виде столбиковой диаграммы. Нужно распределить перечисленные мотивы по группам гигиенических (внешних) факторов и мотиваторов с обоснованием выбора. Нужно определить, факторы какой категории (удовлетворенность или неудовлетворенность трудом) являются для опрашиваемых более важными в трудовой деятельности. При выполнении on-line тестирования автоматически выстраивается мотивационный профиль сотрудника, на котором отражены степень значимости указанных факторов для человека. Считается, что мотивационные факторы, занявшие первое и второе место, определяют климат в коллективе.

Теория мотивации Герцберга имеет много общего с теорией Маслоу [16]. Гигиенические факторы соответствуют физиологическим потребностям и потребностям в безопасности и уверенности в будущем, описанным выше. Факторы мотивации Герцберга сравнимы с потребностями высших уровней Маслоу, то есть потребностями в признании и самовыражении. Однако между этими двумя теориями есть серьезное различие. Маслоу рассматривал факторы, соответствующие гигиеническим, как нечто, вызывающее ту или иную линию поведения. Например, если руководитель дает работнику возможность удовлетворить одну из таких потребностей, то работник в ответ на это станет лучше работать. Герцберг же, напротив, считает, что работник начинает обращать внимание на гигиенические факторы только тогда, когда сочтет их реализацию неадекватной или несправедливой. Для эффективного использования теории Герцберга необходимо составить перечень гигиенических факторов и факторов мотивации и предоставить возможность сотрудникам организации самим определить и указать то, что они предпочитают. Мотивацию по Герцбергу следует воспринимать как вероятностный процесс. То, что мотивирует данного человека в конкретной ситуации, может не оказать на него никакого воздействия в другое время или на другого человека в аналогичной ситуации. Поэтому теория Герцберга не учитывает многих переменных величин, определяющих ситуации, связанные с мотивацией трудовой деятельности. Для того чтобы объяснить механизм мотивации, необходимо рассматривать многочисленные аспекты поведения людей в процессе деятельности и параметры окружающей среды. Реализация этого подхода привела к созданию процессуальных теорий мотивации.

В ходе выполнения опытно-экспериментальной работы в рамках исследований, поддержанных гран- 
тами РГНФ № 12-16-73004a(p) «Построение профессиональной карьеры российскими студентами: национальный и гендерный аспекты» и РГНФ № 13-3601210а2 «Педагогическая поддержка построения профессиональной карьеры провинциальной молодежью» $[1 ; 17 ; 18 ; 19 ; 20]$, наш авторский коллектив на протяжении 2012-2015 учебных годов изучал мотивы выбора профессии молодежью по методике Ф. Герцберга. Экспериментальная выборка респондентов составлялась из числа студентов 4 курса очного отделения факультета технологии и дизайна УлГПУ. Результаты диагностик убедительно показали, что значительную роль для респондентов играют мотивы карьерного роста, содержания профессиональной деятельности, финансовые мотивы, мотивы сотрудничества в коллективе (приведены ведущие мотивы в порядке уменьшения их значимости для респондентов).

Также мы акцентировали внимание на изучении направленности личности в экспериментальных группах для отслеживания взаимосвязи направленности личности и мотивов выбора профессии.

Приведем пример. Экспериментальная выборка составила 16 студентов (2014-2015 учебный год). Результаты проведенной диагностики таковы: направленность на себя (Я) - 25\% опрошенных; направленность на общение $(\mathrm{O})-31,25 \%$ опрошенных; направленность на дело (Д) - 56,25\% опрошенных. При этом было выявлено, что для некоторых опрошенных ведущими являются сразу два вида направленности. Далее вид направленности личности каждого студента из выборки был соотнесен с его ведущими мотивами выбора профессии. Персональный анализ показал, что, к примеру, студенты, для которых характерна направленность на общение, отмечают в качестве ведущего для себя мотива выбора профессии - мотивы сотрудничества в коллективе, а студенты с направленностью на дело (каких большинство в выборке!) - мотивы содержания профессиональной деятельности, что можно расценить как положительный факт.

Таким образом, выполненная опытно-экспериментальная работа подтверждает, что тема нашего исследования сохраняет необходимость дальнейшей разработки. Действительно, мотивы выбора профессии личностью (в нашем случае молодого человека) и ее направленность имеют точки пересечения.

Проблема подготовки современной молодежи к планированию профессиональной карьеры является особо актуальной для российского общества. Высокая степень неопределенности сегодняшней жизни, неясность перспектив социального развития общества, материальные трудности, особенно в небольших провинциальных городах, приводят к тому, многие молодые люди с тревогой смотрят в завтрашний день. Поэтому современное образование должно способствовать тому, чтобы, с одной стороны, человек осознал свои корни и тем самым мог определить место, которое он занимает в мире, а с другой - привить ему уважение к другим культурам и традициям. Дальнейшие изыскания целесообразно вести в отношении разработки теоретических и практических аспектов проблемы подготовки провинциальной молодежи к планированию профессиональной карьеры в полиэтническом Поволжском регионе.

\section{СПИСОК ЛИТЕРАТУРЫ:}

1. Беркутова Д.И., Громова Е.М. Планирование профессиональной карьеры в полиэтническом регионе. Научно-методическое пособие. Ульяновск: Издатель Качалин Александр Васильевич, 2013. 156 с.

2. Громова Е.М., Беркутова Д.И., Горшкова Т.А. Исследование отношения современных российских студентов к построению профессиональной карьеры [Электронный ресурс] // Современные проблемы науки и образования. 2012. № 3. - http://www.scienceeducation.ru/103-6307.

3. Супрунова Л.Л. Поликультурное образование. М.: Академия, 2013. 240 с.

4. Мубинова 3.Ф. Этнонациональное воспитание в современном мире: теоретические и концептуальные подходы: монография. Уфа: Издательство БГПУ имени М. Акмуллы, 2007. 152 с.

5. Кукушин В.С. Этнопедагогика: учебное пособие. М.: Издательство Московского психолого-социального института; Воронеж: Издательство НПО МОДЭК, 2002. 304 c.

6. Климов Е.А. Психология профессионального самоопределения: учебное пособие для вузов. Ростовна-Дону: Феникс, 2004. 302 с.

7. Пряжников Н.С. Профессиональное самоопределение. Теория и практика: учебное пособие. М.: Издательский центр «Академия», 2008. 318 с.

8. Super D.E. The psychology of careers: introduction vocational development. N.Y., 1957. 362 p.

9. Громова Е.М., Беркутова Д.И., Горшкова Т.А. Современные образовательные технологии в подготовке молодежи к планированию карьеры // Теоретические и прикладные вопросы образования и науки: сборник научных трудов по мат-лам Междунар. науч.-практ. конф. 31 марта 2014 г.: в 13 ч. Ч. 6. Тамбов: ООО «Консалтинговая компания Юком», 2014. С. 28-29.

10. Громова Е.М., Беркутова Д.И., Горшкова Т.А. Ценности личности как основа жизненной и профессиональной стратегии // Современные проблемы науки и образования. 2013. № 2. - http://www.scienceeducation.ru/108-9042.

11. Калимуллина О.А. Контент-анализ категории «направленность личности» // Образование и саморазвитие. 2013. № 1. С. 171-177.

12. Спиридонова Н.Ю. Связь направленности личности с выбором профессии в юношеском возрасте: автореф. дис. ... канд. псих. наук. М., 2011. 23 с.

13. Верещагина Л.А. Определение направленности «на себя», «на дело», «на взаимодействие» // Практикум по психологии менеджмента и профессиональной деятельности: учеб. пособие / под ред. Г.С. Никифорова, М.А. Дмитриевой, В.М. Снеткова. СПб.: Речь, 2003. С. 45-47.

14. Шупейко И.Г., Борбот А.Ю., Доморацкая Е.М., Пархоменко Е.М. Основы психологии и педагогики: практикум для студентов всех специальностей и всех форм обучения. Минск: БГУИР, 2008. 91 с.

15. Мескон М., Альберт М., Хедоури Ф. Основы менеджмента (Management). М.: Дело, 1997. 704 c.

16. Маслоу А.Г. Мотивация и личность. СПб.: Евразия, 1999. 478 с.

17. Громова Е.М., Беркутова Д.И., Горшкова Т.А. Профессиональная карьера: путь к успеху. Научнометод. пособие. Ульяновск: УлГПУ, 2012. 126 с. 
Горшкова Т.А., Громова Е.М., Беркутова Д.И.

18. Громова Е.М., Беркутова Д.И., Горшкова Т.А. Практикум к курсу «Профессиональная карьера: путь к успеху»: учебно-методическое пособие. Ульяновск: УлГПУ, 2013. $44 \mathrm{c}$

19. Громова Е.М., Беркутова Д.И., Горшкова Т.А. Подготовка современной молодежи к планированию профессиональной карьеры: монография. Ульяновск: УлГПУ, 2013. $170 \mathrm{c.}$

20. Беркутова Д.И., Громова Е.М. Педагогическая поддержка молодежи в планировании карьеры. Научно-методическое пособие. Ульяновск: Издатель Качалин Александр Васильевич, 2014. 96 с.

\section{PERSONALITY ORIENTATION AND MOTIVES OF PROFESSION CHOICE: POINTS OF INTERSECTION}

(C) 2016

T.A. Gorshkova, candidate of pedagogical sciences, associate professor of the Chair of Mathematical Methods and Technological Education

E.M. Gromova, candidate of pedagogical sciences, associate professor of the Chair of Mathematical Methods and Technological Education

D.I. Berkutova, candidate of pedagogical sciences, associate professor of the Chair of Technologies of Vocational Education Ulyanovsk State Pedagogical University, Ulyanovsk (Russia)

Abstract. The paper studies the problem of features of professional career planning by provincial youth. The authors have analyzed the main scientific and methodological approaches concerning a task of peaceful co-existence and mutual enrichment of various cultures as well as in aspect of career pursuing by youth. The Frederik Gertsberg's theory of motivation is considered. F. Gertsberg has created two-factor model where the first group of factors (hygienic) holds the personality at work, the second group (motivators) - motivates to work. Using F. Gertsberg's test it is possible to define the motivation structure and to allocate the prevailing factors of satisfaction or dissatisfaction with work. Experimental selection of respondents constituted from the rates of 4-year-full-time-students of Technology and Design Department of UISPU. The respondents' diagnosing was carried out according to the F. Gertsberg's test for tracking the interrelation of the personality orientation and motives of profession choice. B. Bass's orientation questionnaire was used for identification of personality orientation. This technique allows to reveal the degree of expressiveness of three main orientations of the personality: self orientation, partner interaction and task orientation. The results of the carried-out diagnostics prove that motives of profession choice and personality orientation have points of intersection. These materials can serve as a basis for further developments of theoretical and practical aspects of the problem of professional career planning by provincial youth.

Keywords: profession; profession choice; professional career; provincial youth; polyethnicity; polyethnical region; professional identification; professional identity; student; personality orientation; theory of motivation of F. Gertsberg; hygiene factors; motivators.

УДК 378.09

\section{ПРОБЛЕМА ОЦЕНКИ КАЧЕСТВА ПОДГОТОВКИ ВЫПУСКНИКОВ СПЕЦИАЛИЗИРОВАННЫХ ВУЗОВ}

О.Н. Ежова, кандидат психологических наук,

профессор кафедры управления и информационно-технического обеспечения деятельности УИС

Н.И. Улендеева, кандидат педагогических наук, доцент кафедры управления и информационно-технического обеспечения деятельности УИС Самарский юридический институт Федеральной службы исполнения наказаний, Самара (Россия)

Аннотация. В данной статье анализируется проблема оценки степени сформированности у выпускников специализированных вузов компетенций, определённых государственным стандартом высшего образования и ведомственным заказом. Рассматривается существующая практика и подходы к формированию фонда оценочных средств. В работе представлены требования к оценочным средствам для проверки сформированности компетенций: интегративность, проблемно-деятельностный характер заданий, ориентация на применение умений и знаний в нетиповых ситуациях, актуализация в заданиях содержания профессиональной деятельности, экспертиза в профессиональном сообществе, связь критериев с планируемыми результатами. Данные требования рассмотрены для инновационных форм контроля: уровневый тест (узнавание - подстановка - продуктивная деятельность - принятие решений в проблемных ситуациях); тест-действие (практическое испытание); ситуационный тест (анализ ситуации из будущей профессиональной деятельности). Отдельное внимание в работе отведено рассмотрению такой формы оценки профессиональных компетенций как межкафедральные учения, которые позволяют проверить сформированные специальные компетенции у курсантов, когда обучающие на практике демонстрируют свои знания, умения, навыки, а также личностные качества, позволяющие им осуществлять свою профессиональную деятельность. Разработанные формы оценки профессиональных компетенций курсантов и слушателей специализированных вузов могут служить основой для дальнейшего координирования процесса определения содержания образования, а также с большей степенью логичности и 